\title{
ARTIGO TÉCNICO \\ DISTRIBUIÇÃO LONGITUDINAL E GERMINAÇÃO DE SEMENTES DE MILHO COM EMPREGO DE TRATAMENTO FITOSSANITÁRIO E GRAFITE
}

\author{
ROBERTO JASPER ${ }^{1}$, UWE JANSZEN ${ }^{2}$, MÔNICA JASPER ${ }^{2}$, LUIZ C.GARCIA ${ }^{3}$
}

\begin{abstract}
RESUMO: Teve-se o objetivo de avaliar as formas de se misturar o lubrificante sólido grafite nas sementes de milho, as dosagens e a influência desse na distribuição longitudinal e na germinação, em sementes sem e com tratamento fitossanitário, em mecanismo dosador com disco perfurado horizontal. Os fatores analisados foram: distribuição longitudinal das sementes (espaçamentos falhos, múltiplos e aceitáveis) e a porcentagem de germinação aos 7 e aos 14 dias após a instalação no germinador. Concluiu-se que o tratamento fitossanitário aumentou os espaçamentos falhos e múltiplos e reduziu os espaçamentos aceitáveis. O emprego de grafite reduziu os espaçamentos falhos e múltiplos e elevou os espaçamentos aceitáveis. A melhor forma de mistura do grafite ocorreu na máquina de tratamento fitossanitário de sementes. A distribuição longitudinal alcançou seu ponto ótimo com a dosagem de grafite de $3,37 \mathrm{~g} \mathrm{~kg}^{-1}$ de semente. As variáveis tratamento fitossanitário, mecanismo dosador e grafite não influíram na germinação das sementes de milho.
\end{abstract}

PALAVRAS-CHAVE: disco perfurado horizontal, espaçamentos aceitáveis, semeadora.

\section{LONGITUDINAL DISTRIBUTION AND GERMINATION OF CORN SEEDS WITH THE USE OF PHYTOSANITARY TREATMENT AND GRAPHITE}

\begin{abstract}
The aim was to evaluate the ways of mixing the solid lubricant graphite with corn seeds, the graphite rates, and its influence on seed longitudinal distribution and germination, with and without phytosanitary treatment, using a horizontal seed plate. The factors analyzed were: seed longitudinal distribution (skips, multiple seed drops, and acceptable spacings) and the germination rates at 7 and 14 days after placement in the germinator. It was concluded that the phytosanitary treatment increased the skips and multiples and decreased the acceptable spacings. The use of graphite decreased the number of skips and multiples and increased the acceptable spacings. The best graphite mixture occurred in the seed treatment machine. The longitudinal distribution reached its excellent point with the dosage of graphite of $3.37 \mathrm{~g} \mathrm{~kg}^{-1}$ of seed. Phytosanitary treatment, metering system, and graphite did not influence the germination of the corn seeds.
\end{abstract}

KEYWORDS: horizontal seed plate, acceptable spacing, seeder.

\section{INTRODUÇÃO}

A qualidade na distribuição longitudinal das sementes com disco perfurado horizontal está relacionada com o ângulo de repouso das sementes no depósito, o teor de água, a presença de material estranho, a orientação das partículas e, principalmente, a rugosidade da superfície da semente (MOHSENIM, 1974).

\footnotetext{
${ }^{1}$ Eng ${ }^{\text {o }}$ Agrônomo, Professor, Universidade Estadual de Ponta Grossa, UEPG, Ponta Grossa - PR, Fone: (0XX42) 9109.5010, jasper@uepg.com.br.

${ }_{2}^{2}$ Acadêmico de Agronomia, Universidade Estadual de Ponta Grossa, UEPG, Ponta Grossa - PR.

${ }^{3}$ Eng ํㅡㄹ Agrônomo, Pós-Graduando em Proteção de Plantas, Faculdade de Ciências Agronômicas, UNESP, Botucatu - SP.

Recebido pelo Conselho Editorial em: 24-10-2003

Aprovado pelo Conselho Editorial em: 24-01-2006
} 
O tratamento fitossanitário de sementes promove alteração na distribuição de sementes por disco perfurado horizontal, devido ao fato de que os principais produtos do mercado conferem certa aderência às sementes, dificultando o enchimento das células e, conseqüentemente, o desempenho desse sistema (MANTOVANI et al., 1999). Segundo MANTOVANI et al. (1999) e HENTSCHKE (2002), o problema de escoamento pode ser facilmente solucionado misturando-se à semente o lubrificante sólido grafite, por ser inerte e por minimizar o coeficiente de atrito entre as sementes e dessas com as partes do mecanismo dosador, diminuindo o ângulo de repouso e, conseqüentemente, facilitando a adequação das sementes nos orifícios do disco.

MANTOVANI et al. (1999) concluíram que a dosagem do grafite deve ser 4,0 $\mathrm{g} \mathrm{kg}^{-1}$ de semente. Já a SOCIDISCO (2003) recomenda de 0,38 a $1,25 \mathrm{~g} \mathrm{~kg}^{-1}$ de semente, dependendo das características das sementes e da semeadora. Os autores, porém, não mencionam se existe distinção na dosagem de grafite para sementes sem e com tratamento fitossanitário, qual a melhor forma de mistura e se há influência do lubrificante sólido no potencial germinativo da semente.

Ao avaliarem o efeito do tratamento de sementes com fungicidas na emergência de plântulas de milho, CASA et al. (1995) concluíram que todos os produtos fitossanitários utilizados não prejudicaram significativamente tal processo. OLIVEIRA et al. (2000) não identificaram alterações significativas nas qualidades fisiológicas das sementes de milho distribuídas pelos discos perfurados da semeadora-adubadora.

O objetivo deste trabalho foi avaliar as formas de misturar o lubrificante sólido grafite nas sementes de milho, dosagens e a influência desse na distribuição longitudinal e na germinação, em sementes sem e com tratamento fitossanitário.

\section{MATERIAL E MÉTODOS}

As etapas do experimento referentes ao tratamento fitossanitário, formas de mistura do grafite e distribuição longitudinal das sementes foram realizadas na empresa Socidisco, localizada em Ponta Grassa - PR. A parte do experimento relacionada à germinação foi desenvolvida no Laboratório de Sementes do curso de Agronomia da Universidade Estadual de Ponta Grossa, UEPG, em agosto de 2002.

O delineamento experimental adotado foi o inteiramente casualizado, em esquema fatorial $2 \times 3 \times 4$ (sementes de milho sem e com tratamento fitossanitário x mistura de grafite e sementes na máquina de tratamento fitossanitário, no tambor giratório com eixo excêntrico e no reservatório de sementes do mecanismo dosador x $0 ; 1,25 ; 2,50$ e $3,75 \mathrm{~g}$ de grafite por $\mathrm{kg}$ de sementes). As variáveis analisadas foram a distribuição longitudinal das sementes (espaçamentos falhos, múltiplos e aceitáveis) e a porcentagem de germinação aos 7 e aos 14 dias após instalação no germinador (com amostras de sementes que não passaram e que passaram pelo mecanismo dosador).

Utilizou-se de um lote de semente de milho de $120 \mathrm{~kg}$, do híbrido D-766, classificadas na peneira C3C. O tratamento fitossanitário com carbofuran $\left(6,98 \mathrm{~g} \mathrm{~kg}^{-1}\right.$ semente $)$ e carboxin-tiram (0,5-0,5 $\mathrm{g} \mathrm{kg}^{-1}$ semente) - Furazin $310 \mathrm{TS}^{\circledR}$ e Vitavax-thiram $200 \mathrm{SC}^{\circledR}$ - foi aplicado em $60 \mathrm{~kg}$ de sementes, em tambor giratório com eixo excêntrico (ANDREI, 1999). Após a secagem das sementes em ambiente controlado $\left(25^{\circ} \mathrm{C}\right.$ e $50 \%$ UR) por $24 \mathrm{~h}$, misturou-se o grafite nas sementes, sem e com tratamento fitossanitário, na máquina de tratamento químico GRAZMEC MTS - 60, no tambor giratório com eixo excêntrico e no reservatório de sementes do mecanismo dosador utilizado no experimento. No reservatório, o grafite foi colocado sobre as sementes e misturado manualmente, antes do início do registro dos dados sobre distribuição longitudinal.

Empregou-se o disco perfurado horizontal e o anel indicados pela empresa produtora da semente. O disco horizontal NA11,5R possuía 189,5 mm de diâmetro, 4,0 $\mathrm{mm}$ de espessura e 28 perfurações. 
As perfurações, em formato cônico, possuíam 11,5 e 12,5 mm de diâmetro, na face superior e inferior do disco, respectivamente. O anel AM000 apresentava dimensões de 189,5 mm de diâmetro e 4,3 $\mathrm{mm}$ de espessura. A abertura no anel para a passagem das sementes tinha 27,8 x 16,6 mm.

Os testes de distribuição longitudinal de sementes ocorreram em bancada com suporte para acoplamento do sistema dosador de uma semeadora, de disco perfurado horizontal, fixado em uma estrutura metálica, na extremidade de uma esteira carpetada de $0,20 \times 9,66 \mathrm{~m}$, girando a $1,54 \mathrm{~m} \mathrm{~s}^{-1}$. A esteira era forçada, pela estrutura da bancada, a adquirir a forma de "V" no trecho em que o tubo condutor depositava a semente, minimizando o deslocamento longitudinal da semente ao longo da esteira. O sistema foi acionado por motor elétrico de $0,735 \mathrm{~kW}(1,0 \mathrm{cv})$. A velocidade tangencial do disco foi de $0,14 \mathrm{~m} \mathrm{~s}^{-1}$, portanto, dentro das recomendações de DELAFOSSE (1986). A bancada estava munida com célula fotoelétrica que registrava o número de orifícios do disco horizontal que passavam pelo tubo que conduzia a semente do mecanismo dosador à esteira. A relação de engrenagens permitia a passagem de um orifício do disco pelo tubo condutor de sementes a cada 0,17 segundos. $O$ tubo condutor apresentava comprimento de $0,35 \mathrm{~m}$ e aberturas de 45 x $30 \mathrm{~mm}$ (próximo ao disco) e 30 x $15 \mathrm{~mm}$ (próximo à esteira).

Os registros dos dados deram-se na extremidade da esteira oposta ao mecanismo dosador, pela avaliação visual dos espaçamentos entre sementes depositadas na esteira carpetada em movimento. A avaliação foi embasada na ASSOCIAÇÃO BRASILEIRA DE NORMAS TÉCNICAS (1989), que considera como aceitáveis todos os espaçamentos entre sementes de 0,5 a 1,5 vez o espaçamento médio esperado $(\mathrm{EM}) \mathrm{de} 0,26 \mathrm{~m}$. Os valores obtidos fora desse limite foram considerados como espaçamentos falhos (acima de 1,5 vez EM) ou múltiplos (abaixo de 0,5 vez EM).

O sistema dosador empregado, em todos os tratamentos, teve as folgas entre disco, anel e base corrigidos pelo Seajuste ${ }^{\circledR}$ (anel metálico móvel, fixado na base intermediária). A distância entre o disco e o gatilho raspador era de, no máximo, $1,5 \mathrm{~mm}$. Todas as coletas de dados ocorreram com, no mínimo, 4,0 kg de sementes no reservatório, para atender às recomendações de CHHINNAN et al. (1975).

No teste de germinação, os rolos de papel toalha, umedecidos por água, foram levados à câmara de germinação $\left(25 \pm 5{ }^{\circ} \mathrm{C}\right.$ e $92 \pm 3 \%$ UR), conforme método indicado por MARCOS FILHO et al. (1987). O parâmetro avaliado foi a porcentagem de germinação das sementes aos 7 e aos 14 dias após a instalação no germinador.

O tamanho da amostra das parcelas foi determinado com base no método proposto por KRANZ (1988), que leva em consideração a estabilização da média e o desvio-padrão da variável estudada. O número de repetições foi de quatro para todos os tratamentos. A homocedasticidade das variâncias foi verificada pelo teste de Hartley e as variâncias das médias dos fatores analisadas pela aplicação dos testes estatísticos paramétricos " $F$ ", " $t$ " e regressão polinomial, a 5\% de probabilidade.

\section{RESULTADOS E DISCUSSÃO}

A média e o desvio-padrão dos dados sobre distribuição longitudinal estabilizaram-se em 500 orifícios, limitando-se aí o tamanho das parcelas. No teste de germinação, a estabilização ocorreu com 50 sementes por rolo de papel toalha (KRANZ, 1998). Não houve necessidade de transformação das médias para todas as variáveis estudadas, denotando a homocedasticidade das variâncias, pelo teste de Hartley.

O teste "F" das médias dos resultados das avaliações sobre espaçamentos falhos indicou diferença significativa entre os fatores e as interações, com exceção da interação "formas de mistura" e "dosagens do grafite". A análise das variâncias apresentou os seguintes parâmetros estatísticos: média geral $1,17 \%$, coeficiente de variação de $26 \%$ e desvio-padrão de 0,31 . 
Considerando-se a análise dos dados coletados, verifica-se que os índices de espaçamentos falhos para as sementes que passaram por tratamento de sementes são superiores em relação às sementes sem tratamento, em todas as formas de mistura (Tabela 1). Confirmam-se, assim, as conclusões de MOHSENIM (1974) e MANTOVANI et al. (1999) de que o tratamento fitossanitário altera a rugosidade da superfície das sementes e, por conseqüência, a distribuição longitudinal.

TABELA 1. Espaçamentos falhos para as sementes do híbrido D-766, peneira C3C, com emprego de disco horizontal perfurado NA11,5R e anel AM000.

\begin{tabular}{lcc}
\hline \multirow{2}{*}{$\begin{array}{c}\text { Forma de Mistura do Grafite } \\
\text { nas Sementes }\end{array}$} & $\begin{array}{c}\text { Sem Tratamento Fitossanitário } \\
\text { das Sementes }\end{array}$ & $\begin{array}{c}\text { Com Tratamento Fitossanitário } \\
\text { das Sementes }\end{array}$ \\
\cline { 2 - 3 } & \multicolumn{2}{c}{ Espaçamentos Falhos $(\%)$} \\
\hline Depósito de sementes & $0,48 \mathrm{~b}^{(1)} \mathrm{A}^{(2)}$ & $2,02 \mathrm{aA}$ \\
Tambor de tratamento de sementes & $0,59 \mathrm{bA}$ & $1,82 \mathrm{aA}$ \\
Máquina de tratamento de sementes & $0,63 \mathrm{bA}$ & $1,50 \mathrm{aB}$ \\
\hline
\end{tabular}

DMS “tratamento das sementes" dentro de "formas de mistura" 0,22

DMS "forma de mistura" dentro de "tratamento das sementes" 0,26

(1) Médias seguidas de mesma letra minúscula não diferem significativamente, na linha, para o desdobramento "tratamento fitossanitário das sementes" dentro de "formas de mistura do grafite nas sementes" (Teste T - P > 0,05).

(2) Médias seguidas de mesma letra maiúscula não diferem significativamente, na coluna, para o desdobramento "formas de mistura do grafite nas sementes" dentro de "tratamento fitossanitário das sementes" (Teste T - P > 0,05).

No desdobramento das interações entre os fatores "formas de mistura do grafite nas sementes" dentro de "tratamento fitossanitário das sementes", observou-se que não importa a forma de mistura quando não há tratamento fitossanitário. No caso do emprego do tratamento fitossanitário, a menor percentagem de espaçamentos falhos no processo de dosagem das sementes ocorreu quando houve mistura do grafite na máquina de tratamento fitossanitário de sementes, diferindo significativamente das demais formas, denotando a melhor homogeneização da combinação ao se optar por esse processo.

No que se refere ao desdobramento das interações entre os fatores "tratamento fitossanitário das sementes" dentro de "dosagem," observa-se que a percentagem de espaçamentos falhos é significativamente maior para as sementes que passaram pelo tratamento fitossanitário de sementes, em relação às sementes sem tratamento (Figura 1). Tal fato pode ser atribuído à alteração da rugosidade da superfície das sementes causadas pelo tratamento fitossanitário, conforme alertaram MANTOVANI et al. (1999) e HENTSCHKE (2002). Ao se derivar a curva, observou-se que as menores percentagens de falhas, sem e com tratamento fitossanitário, foram obtidas com a dosagem de 3,21 e $3,37 \mathrm{~g}$ de grafite por $\mathrm{kg}$ de semente.

O teste "F" das médias dos resultados das avaliações sobre espaçamentos múltiplos indicou diferença significativa somente para a interação "tratamento fitossanitário das sementes" e "dosagens do grafite". A análise das variâncias resultou nos seguintes parâmetros estatísticos: média geral $1,36 \%$, coeficiente de variação de $37 \%$ e desvio-padrão de 0,50 . A regressão polinomial só foi significativa para sementes com tratamento fitossanitário (Figura 2); portanto, a adição de grafite não alterou a porcentagem de espaçamentos múltiplos para sementes sem tratamento fitossanitário. No caso das sementes tratadas, a menor porcentagem de espaçamentos múltiplos foi alcançada com a dosagem de 3,28 g de grafite por kg de semente, conforme ajuste da curva. Novamente, os resultados corroboram as afirmações de MANTOVANI et al. (1999) e HENTSCHKE (2002). 


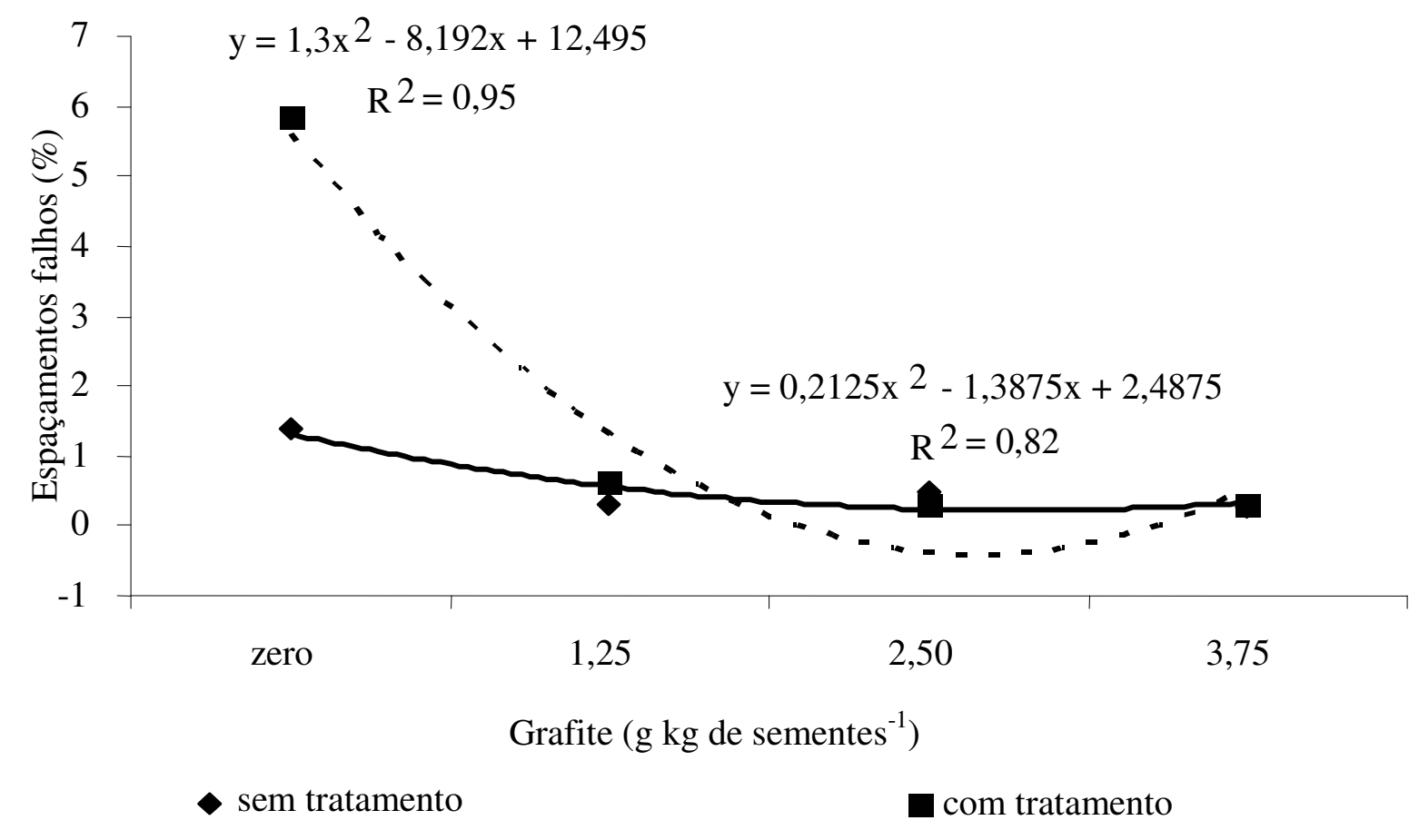

FIGURA 1. Espaçamentos falhos para as sementes do híbrido D-766, peneira C3C, com emprego de disco horizontal perfurado NA11,5R e anel AM000

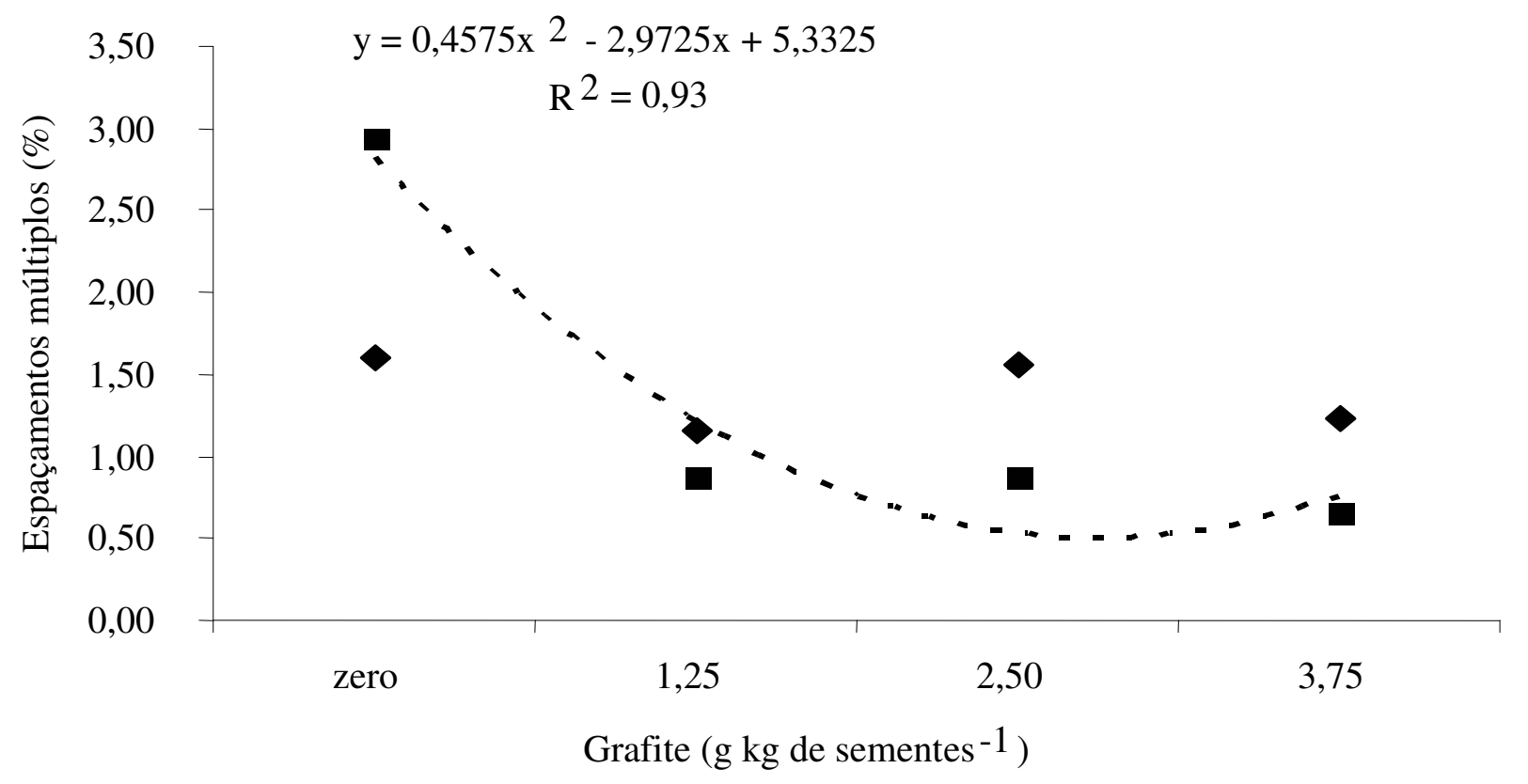

sem tratamento

com tratamento

FIGURA 2. Espaçamentos múltiplos para as sementes do híbrido D-766, peneira C3C, com emprego de disco horizontal perfurado NA11,5R, anel e AM000. 
O teste "F" das médias dos resultados das avaliações visuais sobre espaçamentos aceitáveis indicou diferença significativa entre os fatores e as interações, com exceção da interação "formas de mistura" e "dosagens do grafite". A análise das variâncias indicou os seguintes parâmetros estatísticos: média geral 97,44 \%, coeficiente de variação de $0,56 \%$ e desvio-padrão de 0,54 . Ao se considerarem os dados coletados, verifica-se que as percentagens de espaçamentos aceitáveis para as sementes que não passaram por tratamento de sementes são superiores em relação às sementes com tratamento, em todas as formas de mistura (Tabela 2).

TABELA 2. Espaçamentos aceitáveis para as sementes do híbrido D-766, peneira C3C, com emprego de disco horizontal perfurado NA11,5R e anel AM000.

\begin{tabular}{lcc}
\hline \multirow{2}{*}{$\begin{array}{c}\text { Forma de Mistura do Grafite } \\
\text { nas Sementes }\end{array}$} & $\begin{array}{c}\text { Sem Tratamento Fitossanitário } \\
\text { das Sementes }\end{array}$ & $\begin{array}{c}\text { Com Tratamento Fitossanitário } \\
\text { das Sementes }\end{array}$ \\
\cline { 2 - 3 } & \multicolumn{2}{c}{ Espaçamentos Aceitáveis (\%) } \\
\hline Depósito de sementes & $98,01 \mathrm{a}^{(1)} \mathrm{A}^{(2)}$ & $96,71 \mathrm{bA}$ \\
Tambor de tratamento de sementes & $98,04 \mathrm{aA}$ & $96,73 \mathrm{bA}$ \\
Máquina de tratamento de sementes & $97,93 \mathrm{aA}$ & $97,21 \mathrm{bB}$ \\
\hline
\end{tabular}

DMS “tratamento das sementes" dentro de "formas de mistura" 0,38

DMS "forma de mistura" dentro de "tratamento das sementes" 0,46

(1) Médias seguidas de mesma letra minúscula não diferem significativamente, na linha, para o desdobramento "tratamento fitossanitário das sementes" dentro de "formas de mistura do grafite nas sementes" (Teste T - P > 0,05).

(2) Médias seguidas de mesma letra maiúscula não diferem significativamente, na coluna, para o desdobramento "formas de mistura do grafite nas sementes" dentro de "tratamento fitossanitário das sementes" (Teste T - P > 0,05).

No desdobramento das interações entre os fatores "formas de mistura do grafite nas sementes" dentro de "tratamento fitossanitário das sementes", observou-se que não importa a forma de mistura quando não há tratamento fitossanitário. No caso do emprego do tratamento fitossanitário, as maiores percentagens de espaçamentos aceitáveis no processo de dosagem das sementes ocorreram quando houve mistura do grafite na máquina de tratamento fitossanitário, diferindo significativamente da mistura feita no depósito de sementes do mecanismo dosador e no tambor.

No que se refere ao desdobramento das interações entre os fatores "tratamento fitossanitário das sementes" dentro de "dosagem", verifica-se que a regressão polinomial não foi significativa para sementes sem tratamento fitossanitário. Nas sementes com tratamento fitossanitário, ao se derivar a curva da percentagem de espaçamentos aceitáveis, verifica-se que, na dosagem de 3,24 g de grafite por $\mathrm{kg}$ de semente, se obteve o ponto ótimo. (Figura 3).

As informações levantadas ficaram entre as indicações de MANTOVANI et al. (1999) e da SOCIDISCO (2003), devido às interações dos fatores estudados.

$O$ teste "F" não acusou diferença significativa para os fatores e as interações em se tratando de porcentagem de germinação, para os dados coletados após 7 e 14 dias de instalação no germinador, sendo, respectivamente, média geral de 96,1 e 97,1\%, desvio-padrão de 2,9 e 2,6 e coeficiente de variação de 3,1 e $2,7 \%$. Assim sendo, não houve necessidade da aplicação do teste " $t$ " para a verificação das diferenças entre os tratamentos. Os resultados indicam que as variáveis tratamento fitossanitário, mecanismo dosador e grafite não influíram na germinação das sementes de milho. Confirmam-se, assim, as conclusões obtidas por CASA et al. (1995) e OLIVERIA et al. (2000). 


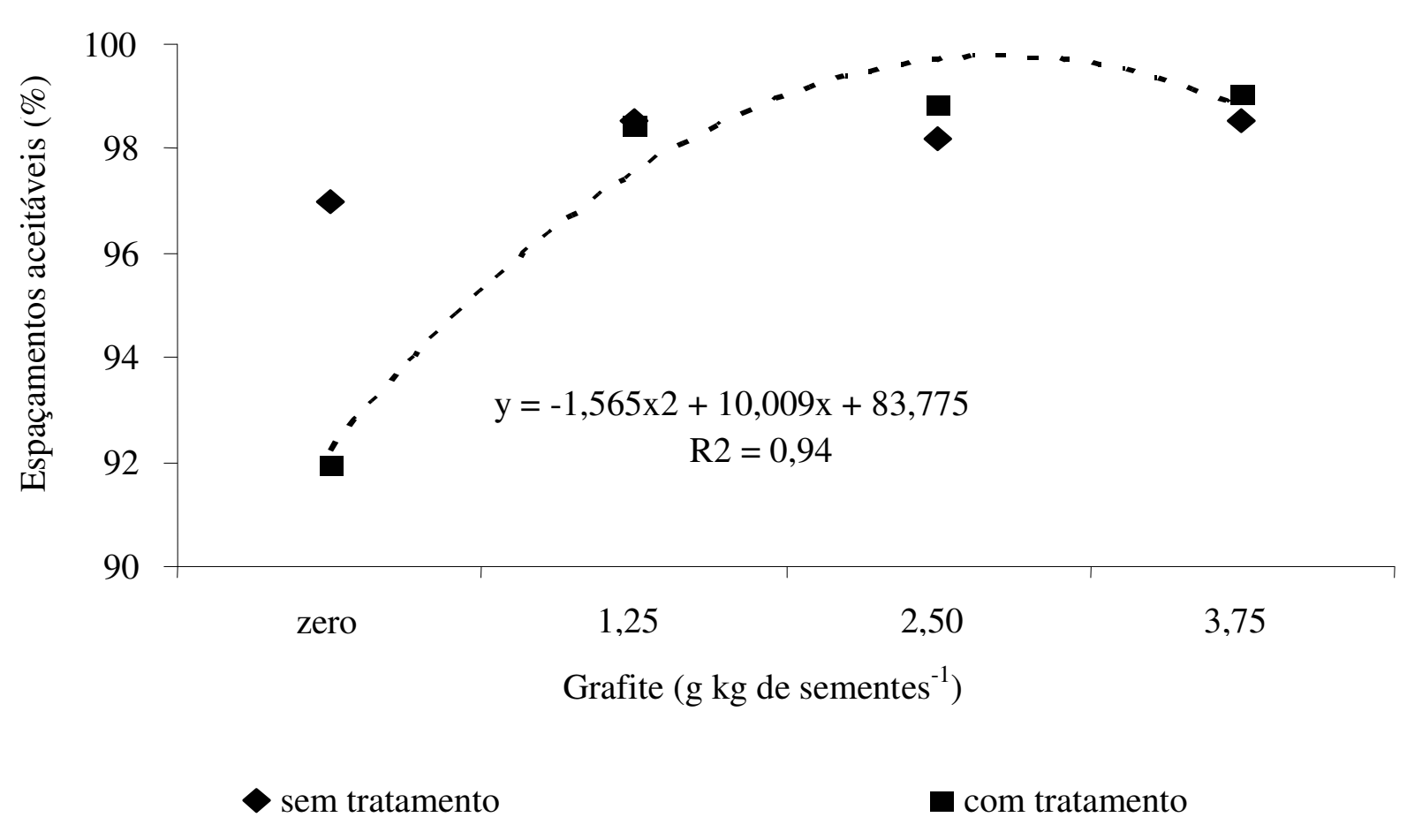

FIGURA 3. Espaçamentos aceitáveis para as sementes do híbrido D-766, peneira C3C, com emprego de disco horizontal perfurado NA11,5R e anel AM000.

\section{CONCLUSÕES}

O tratamento fitossanitário aumentou os espaçamentos falhos e múltiplos e reduziu os espaçamentos aceitáveis. O emprego de grafite reduziu os espaçamentos falhos e múltiplos e elevou os espaçamentos aceitáveis. A melhor forma de mistura do grafite ocorreu na máquina de tratamento fitossanitário de sementes. As variáveis tratamento fitossanitário, mecanismo dosador e grafite não influíram na germinação das sementes de milho.

\section{REFERÊNCIAS}

ANDREI, E. Compêndio de defensivos agrícolas. 6.ed. São Paulo: Andrei, 1999. 285 p.

ASSOCIAÇÃO BRASILEIRA DE NORMAS TÉCNICAS. Semeadora de precisão: ensaio de laboratório/método de ensaio. Projeto de norma 12:02.06-004. Rio de Janeiro, 1989. 21p.

CASA, R.T.; REIS, E.M.; MEDEIROS, C.A.; MOURA, F.B. Efeito do tratamento de sementes de milho com fungicidas, na proteção de fungos do solo, no Rio Grande do Sul. Fitopatologia Brasileira, Brasília, v.20, p.633-7, 1995.

CHHINNAN, M.S.; YOUNG, J.H.; ROHRBACK, R.P. Accuracy of seed spacing in peanuts planting. Transactions of the ASAE, St Joseph, v.18, n.5, p.828-31, 1975.

DELAFOSSE, R.M. Máquinas sembradoras de grano grueso, descripción y uso. Santiago de Chile: FAO, 1986. 48 p.

HENTSCHKE, C. Cultura do milho: planejamento do plantio. Seed News, Pelotas, n.4, p.18-20, 2002.

KRANZ, J. Measuring plant disease. In KRANZ, J.; ROTEM, J. (Ed.). Experimental techniques in plant disease epidemiology. Heidelberg: Springer, 1988. p.35-50. 
MANTOVANI, E.C.; MANTOVANI, B.H.M.; CRUZ, I.; MEWES, W.L.C.; OLIVEIRA, A.C.

Desempenho de dois sistemas distribuidores de sementes utilizados em semeadoras de milho. Pesquisa Agropecuária Brasileira, Brasília, v.34, n.1, p.93-8, 1999.

MARCOS FILHO, J.; CICERO, S.M.; SILVA, W.R. Avaliação da qualidade das sementes.

Piracicaba: FEALQ, 1987. 230 p.

MOHSENIN, N.N. Physical properties of plant and animal materials. New York: Gordan and Breach, 1974. $734 \mathrm{p}$.

OLIVERIA, M.L.; VIEIRA, L.B.; MANTOVANI, E.C.; SOUZA, C. M.; DIAS, G. P. Desempenho de uma semeadora-adubadora para plantio direto, em dois solos com diferentes tipos de cobertura vegetal. Pesquisa Agropecuária Brasileira, Brasília, v.35, n.7, p.1455-63, 2000.

SOCIDISCO. Regulando plantadeiras com a socidisco. Ponta Grossa: Socidisco, 2003. p.24-5. 